\title{
SPATIO-TEMPORAL STUDY OF THE DETERMINANTS OF RESIDENTIAL SATISFACTION IN NEW YORK CITY DURING COVID-19 USING CROWDSOURCED DATA
}

\author{
S. Azad ${ }^{1 *}$, M. Ghandehari ${ }^{1}$ \\ ${ }^{1}$ Department of Civil and Urban Engineering, Tandon School of Engineering, New York University. Brooklyn, NY 11201 USA - \\ (shams.azad,masoud)@nyu.edu
}

KEY WORDS: Noise, Crime, NYC311, NYPD 911, COVID-19, Change Dynamics, Residential Satisfaction

\begin{abstract}
:
Residential satisfaction, an indicator of the quality of life, can be conceptualized with the objective and subjective evaluation of the physical and ecological characteristics of dwellings and neighbourhoods. The majority of the New Yorkers remained indoors during the COVID-19 pandemic, increasing the importance of the residential environment and satisfaction like never before. Noise and safety are two major determinants of residential satisfaction that changed much during the pandemic lockdown. We used citizen-generated non-emergency (NYC311) and emergency (NYPD911) complaint data to investigate the spatial and temporal change dynamics of complaints related to noise and safety. In the noise domain, we focused on NYC311 complaints associated with the noise from neighbours, streets, and illegal fireworks. In the safety domain, we examined the change of both physical and economic safety. For physical safety, we used the NYPD 911 data related to burglary and vehicle larceny, where for economic safety, we used NYC311 complaints correspond to price gouging. We spatially aggregated the complaints at the census tract level (total $=2123$ ) and performed Welsch's t-test to identify the change dynamics of the satisfaction during the pandemic for different socioeconomic factors. We found the overall residential satisfaction decreased during the pandemic with extreme noise exposure and inadequate safety. The study also found the economic and racial disparity in residential satisfaction during the pandemic, as with statistical significance, the complaints regarding noise, physical and financial safety generated from the Black, Latinx, and impoverished communities were significantly higher than White, Asian and affluent communities.
\end{abstract}

\section{INTRODUCTION}

Residential satisfaction can be described as the individual's level of approval with conditions in their residential neighbourhood (Terzano, 2014). It is considered a notable indicator of the quality of life and happiness (Amole, 2009; Stauss and Neuhaus, 1997; Wu et al., 2020). Residents' independent evaluations of their residence and neighbourhood also determine the level of action needed from the authority to improve the general living condition. Residential satisfaction not only associates with the residents but also influences policymaking. As a result, the topic had been studied widely by researchers of different domains, including sociology, psychology, planning, and geography (Lu, 1999). Residential satisfaction can be conceptualized with the combination of objective and subjective perceptions of the residents (Adriaanse, 2007; Amole, 2009; Pishgahi and Partovi, 2020). The objective part can be subdivided into contextual and compositional factors. The contextual factors include the physical characteristics of the dwellings and the surrounding neighbourhoods, where the compositional factors refer to the attributes associated with household composition. These objective factors couples with the peoples' subjective assessment of the physical and social environment to encapsulate the overall satisfaction (Galster and Hesser, 1981). As the subjective aspect plays a vital role in residential satisfaction, there is no concrete and unique definition of the determinants of this subject. Professionals from different domains focus on various aspects, such as determining the level of satisfaction the architects emphasize on physical features of the residence, where planners and policymakers stress more on social and commercial aspects (Sam et al., 2012).

New York City (NYC) was the initial epicenter of COVID-19 in the United States. (NYC Health, 2020a). To slow the spread of the virus, the city went under a complete shutdown on March 20th, 2020 (Feuer and Higgins-Dunn, 2020; McKinley and Gold, 2020). During that period, an unprecedented number of New Yorkers kept themselves indoors. Except for essential workers, all employees worked, and all students schooled from home. As a result, the effect of the residential environment on them was more significant than ever before.

Noise and safety are two important determinants of residential satisfaction (Abdullah et al., 2020; Emami and Sadeghlou, 2020; Youssoufi et al., 2020) that changed significantly in the city during the pandemic lockdown. Noise pollution significantly impacts human health. Along with auditory effects, noise exposures have been linked to a wide range of health effects, including but not limited to annoyance, sleep disturbance, cardiovascular disease, and impairment of cognitive performance in children (Basner et al., 2014; Ising and Kruppa, 2004). As people spend all day at home during the pandemic, the effect of residential noise exposure cannot be ignored as it has a significant association with psychological stress (Bosch et al., 2021; Daiber et al., 2020; Ng, 2000; Tao et al., 2020). It was reported that the people became exhausted by the noise coming from neighbours and streets and filed an incredible number of noise complaints during the pandemic (Krauth, 2020). From the beginning of June 2020, the city experienced an unusual number of illegal fireworks incidents that kept the residents awake at night. In comparison with 2019, the fireworks-related complaints increased by $4000 \%$ in the first two weeks of June 2020 (Hicks

\footnotetext{
* Corresponding author
} 
and Marsh, 2020). To control the situation, the city mayor announced to deploy a task force to crack down on the illegal use and distribution of fireworks (Zaveri and Gold, 2020).

Safety is also a major determinant of residential satisfaction among the residents (Demao, 1991; Feldmane, 2020). NYC saw an uptick in serious crimes during the pandemic. According to NYPD, 2020 was a year of historic low total crime index for the city. However, there was a significant spike in the violent crimes, including homicides, shooting, car theft, and burglaries, with a $29 \%$ increase in annual gun arrest in 2020 compared to 2019 (NYPD Newsroom, 2021). Along with physical safety, in many cases the city failed to ensure the economic safety of its residents (NYC Consumer and Worker Protection, 2020). Here we looked into price gouging as an indicator for economic safety (Noy, 2018). Just before the announcement of the stay-at-home order, people became panicked and rushed into the retail stores to pile up stocks of essential products (Knoll, 2020). Many retail stores took advantage of this dire situation and increased the price of products having higher demand. On June 6th, the governor of New York state signed legislation (S.8189/A.10270) to ban price gouging on personal protective equipment (New York State Pressroom, 2020).

This study aimed to identify the change dynamics of noise and safety, two significant indicators of residential satisfaction, during the pandemic, using citizen generated NYC311 and NYPD 911 dataset. NYC residents have the privilege to report non-emergency issues with 311 and emergency concerns with the 911 hotline. In the noise domain, we included noise from neighbours (residential noise), noise from streets (vehicular noise), and noise from illegal fireworks. All these data came from the NYC311 dataset. In the safety domain, we considered two aspects: physical and economic. For physical safety, we used the NYPD 911 dataset and considered the complaints related to burglary and vehicle larceny, where for economic safety we used the NYC311 dataset related to price gouging. We investigated the spatial and temporal change dynamics of these complaints. Some studies concluded that socioeconomic status (SES) could be a dominant factor for residential satisfaction (Jagun et al., 1990; Kshetrimayum et al.; 2020; Najib et al., 2011; Norouzi et al., 2020; Waziri et al., 2014). Here, we examined how the change dynamics of noise and safety during the pandemic vary within SES like race, income, and education. We used Welch's t-test to check the statistical significance of the variability. We also considered the rate of COVID-19 infection for the t-test to investigate if the change in noise and crime associate with the severity of the pandemic.

\section{DATA AND METHODS}

On March 9th, 2003, New York City launched the NYC311 service to allow its residents to report non-emergency concerns and problems, aiming to increase the accessibility and responsiveness of city agencies and ensure better public service (NYC Office of the Mayor, 2013). Residents can report their issues 24 hours a day, seven days a week, 365 days a year, and in nearly 180 languages through the call centre, online, mobile app, social media, or texting. In 2020, 311 call centre alone handled a record of 23.5 million calls (NYC Office of the Mayor, 2020). NYC311 has 184 major complaint types, and each major complaint is divided into subcategories. Each year, the noiserelated complaints top the total number of calls. The data of the NYC311 service request calls from 2010 to present may be found in NYC open data portal (NYC Open Data, 2021a). The data is geocoded, with the longitude and latitude value of the incidents associated with the calls. We collected residential noise, vehicular noise, illegal fireworks, and consumer retail store complaints data between January 2019 and December 2020 from the NYC311 dataset.

While 311 is the dedicated hotline for non-emergency situations, the city residence reports emergency issues through the 911 hotline. Each 911 call is received by a police officer. If the call is related to a crime incident, then the police call taker shares the details with the police dispatcher who mobilizes the police unit. Police call taker includes call taker of emergency medical service (EMS) in the call if the reporting is related to emergency health or includes the Fire department call taker if the issue is related to fire (NYC 911 Reporting, 2021). We used NYPD 911 reporting data where each entry in the dataset represents a crime incident in the city with geocoordinates. The dataset is open-sourced and available at NYC open data portal (NYC Open Data, 2021b). From the dataset, we used the total number of crimes, crime related to vehicle larceny, and burglary between 1st January 2019 and 31st December 2020.

With NYC311 and NYPD911 dataset, we created time-series graphs to investigate the temporal and developed heatmaps to observe the spatial trends of the complaints. Then we aggregated the complaints between April and November in 2019 and 2020 at the census tract level. We normalized the 2019 values by respective census tract population to get the number of incidences of each category per 100,000 population. Population normalized complaints in 2019 represent the pre-pandemic scenario for noise and safety at the census tract level. In the case for 2020, we have calculated the percent change in complaints for each census tract. To observe how the complaints regarding noise and safety vary according to different SES factors, we performed the statistical ttest with the variables including median family income, race, and educational attainment (bachelor or more) at the census tract level. We Collected data for these SES factors from the American Community Survey (U.S. Census Bureau, 2018). Figure 1 shows the spatial distribution of median household income and percent of the Black and Latinx population. We also investigated changes of noise and safety versus severity of the pandemic. In this regard, we collected the COVID-19 infection dataset for New York City from the NYC department of health and mental hygiene (NYC Health, 2020b). We used the cumulative number of positive cases as of 30th November 2020, per 100,000 population at the zip code level to measure the spread. Later, we spatially aggregated the zip code level COVID-19 data into census tract level to match with other census data.

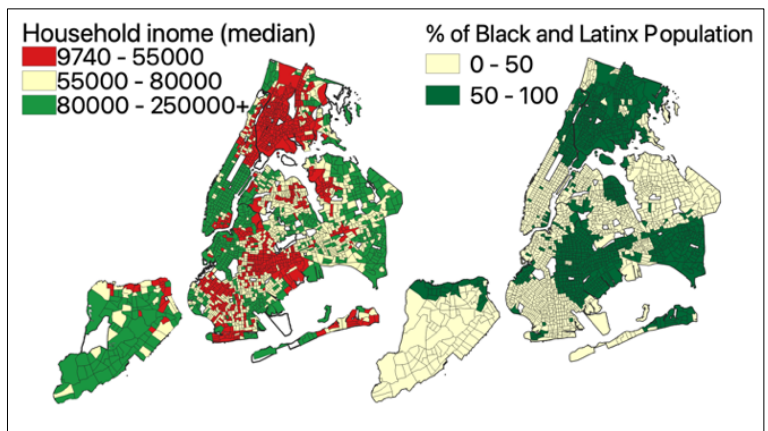

Figure 1. (left) median household income and (right) percentage of Black and Latinx population at census tract level

\section{SPATIO-TEMPORAL TRENDS}

In 2019, NYC311 complaints relating to residential noise were around 640 per day, which almost doubled in 2020, with an average of 1115 calls every day. Comparing the heatmap (Figure 2) with the Household income map of New York City (Figure 1), we can say that most of the 311 calls relating to residential noise appeared from financially disadvantaged neighbourhoods in 2019 , indicating the economic disparity in noise exposure in the 
city during the pre-pandemic time. From Figure 3, it is clear that residential noise complaints started to rise after the enforcement of the stay-at-home order. As more people remained indoors, they became exhausted by the noise from neighbours and filed 311 complaints.

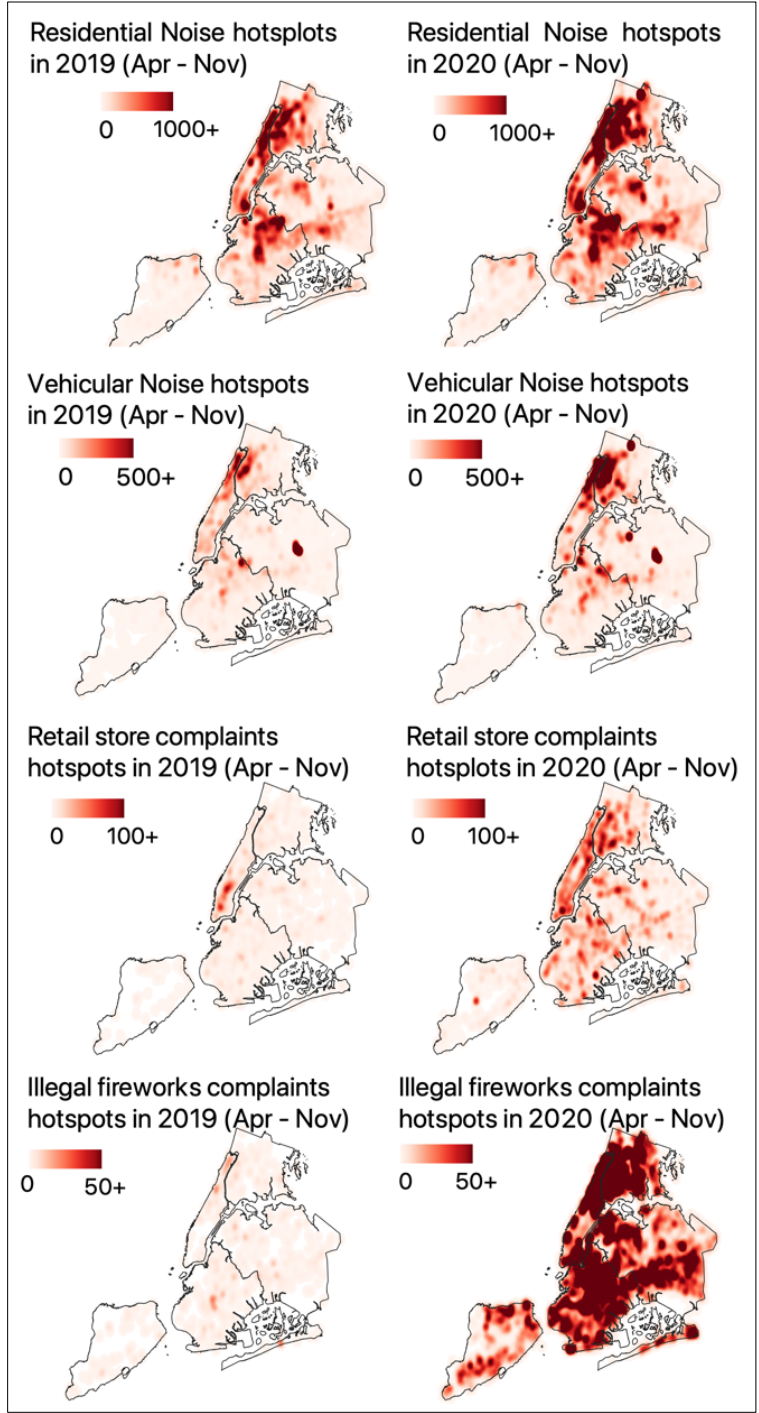

Figure 2. Heatmaps show the spatial distribution of 311 complaints related to residential noise, vehicle noise, consumer retail store, and illegal fireworks for 2019 (left) and 2020 (right). Kernel density estimation is done with 1-km bandwidth and 100meter pixel size.

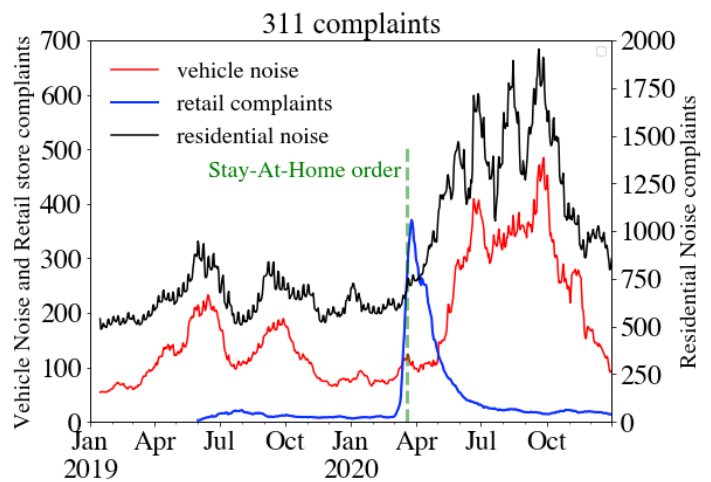

Figure 3. Fifteen days rolling average residential noise (secondary axis), vehicular noise and retail store complaints (primary axis)

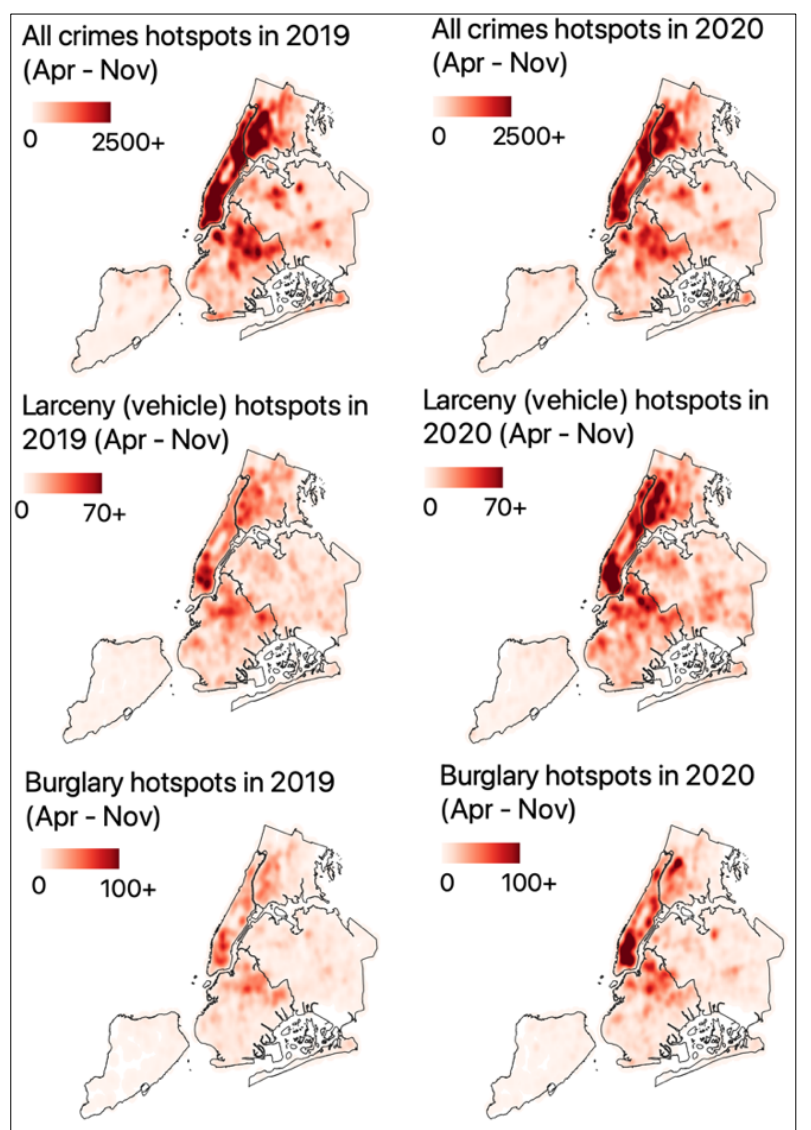

Figure 4. Heatmaps show the spatial distribution of 911 complaints related to all crimes, vehicle larceny, and burglary for 2019 (left) and 2020 (right). Kernel density estimation is done with 1-km bandwidth and 100-meter pixel size.

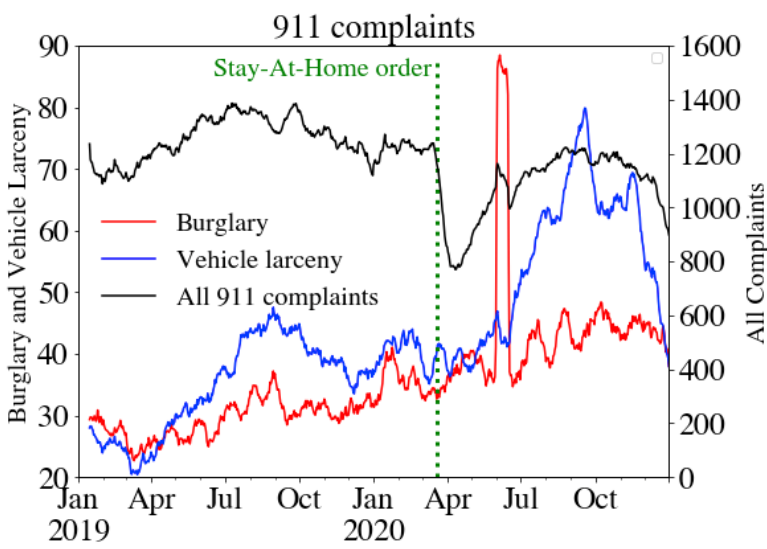

Figure 5. Fifteen days rolling average of total 911 complaints (secondary axis), burglary and vehicle larceny complaints (primary axis)

Residential noise complaints are divided into four subcategories in the NYC311 dataset. Compared to 2019, in 2020 the residential noise complaints regarding loud music/party increased by $98 \%$, banging/pounding by $33 \%$, loud talking by $36 \%$, and loud television by $36 \%$. Vehicular noise complaints followed almost the same temporal trend as residential noise complaints (Figure 3). On average, daily vehicular noise complaints in 2019 were 118 , which nearly doubled in 2020 with 222 complaints per day. There are three types of vehicular noise complaints recorded in the 311 datasets: car/truck music, car/truck horn, and engine idling. The complaints regarding 
car/truck music were increased by $157 \%$ in 2020 compared to 2019 , where the car/truck horn by $8 \%$ and engine idling by $33 \%$. From the heatmap in Figure 2, we found the upper Manhattan and the west Bronx were the prime hotspots for vehicular noise. New York City had seen a significant spike in consumer complaints regarding retail stores at the beginning of the stay-athome order. Consumer retail store complaints include false advertising, overcharging, refusing an exchange, return, or refund, selling damaged or defective goods, failing to deliver goods or services, failing to post prices or provide a complete receipt, providing an illegal receipt, selling prohibited items (NYC 311, 2021). Reports from several news sources confirmed that price gouging was the primary source of retail store complaints during the pandemic shutdown (abc7NY, 2020; Greenbaum, 2020; Shahgholi, 2020). In 2019, the city-wide total consumer complaints regarding retail stores were around 2500 . The number of complaints increased by $740 \%$ in 2020 , with a total of 21,000 complaints. Heatmap shows (Figure 2) that in 2019, most retail store complaints came from the wealthiest part of the city: the mid-town and downtown Manhattan. During the COVID lockdown, the complaints came from all around the city with the highest concentration in uptown Manhattan and Bronx. New York City experienced an unprecedented number of illegal fireworks incidents in 2020. These illegal fireworks incidents were fuelled by a social protest and not directly connected with the pandemic lockdown (Kilgannon and Kim, 2020). There were almost fifty thousand 311 complaints related to illegal fireworks in 2020 where the number was just over nine hundred in 2019. During the pandemic lockdown, people are particularly disturbed by the firework incident at night. Around $80 \%$ of the total 311 calls relating to illegal fireworks occurred between 9 $\mathrm{pm}$ and $2 \mathrm{am}$. From the heatmap, it is clear that the fireworks complaints came from all parts of the city.

From the 911 NYPD complaint dataset, we found that the total crime decreased by $11.5 \%$ in 2020 compared to 2019 . In 2019 , the city made 457,543 emergency calls, which dropped to 404,892 in 2020. From Figure 5, we found a tremendous drop in daily 911-complaints right after the stay-at-home order. The city generated on average 1218 calls per day in February 2020. After the stay-at-home order, it dropped by $32 \%$ in April 2020, with a daily average of only 825 calls. Although the overall crime reduced during COVID, more serious crimes like shooting and homicide increased significantly in the city (NYPD Newsroom, 2021). We looked into the change dynamics of the crimes includes burglary and vehicle theft. We found a $43 \%$ increase in burglary and a $50.4 \%$ increase in vehicle larceny in 2020 compared to 2019. The time-series graph (Figure 5) shows a long-term rising trend of burglary in the city that started before the pandemic. However, in the first week of June 2020, the city experienced the highest number of burglary incidents in two years. From the heatmaps (Figure 4), we observed a significant increase in burglary in downtown and midtown Manhattan, downtown Brooklyn and parts of Bronx. Similar to burglary, vehicle larceny started to rise in June 2020, peaked in August, and started to decline from November. In 2019, the affluent midtown and downtown Manhattan was the hotspot for vehicle larceny (Figure 4). However, in 2020 larceny increased all around the city, and the west Bronx became a new hotspot along with the old ones.

\section{STATISTICAL TEST FOR SOCIOECONOMIC FACTORS}

We used Welch's t-test to observe the change dynamics of residential satisfaction based on the social and demographic characteristics of the city. The t-test is a widely used statistical hypothesis test to measures whether the average value differs significantly across samples (Kim, 2015; Ruxton, 2006). Welch's T-statistics can be formulated as,

$$
t=\frac{\overline{x_{1}}-\overline{x_{2}}}{\sqrt{\left(\frac{s_{1}^{2}}{n_{1}}+\frac{s_{2}{ }^{2}}{n_{2}}\right)}}
$$
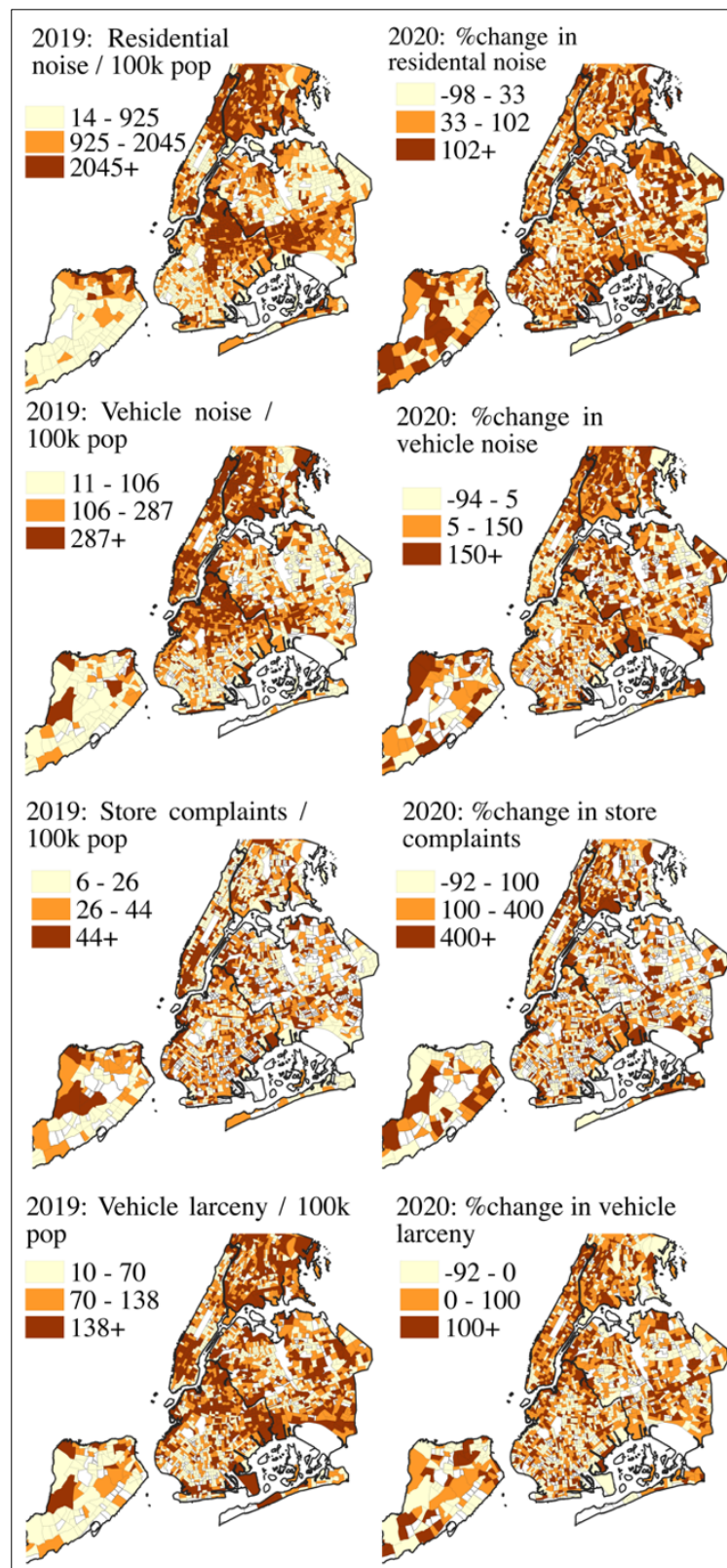

2020: \%change in store

2019: Burglary / 100k pop
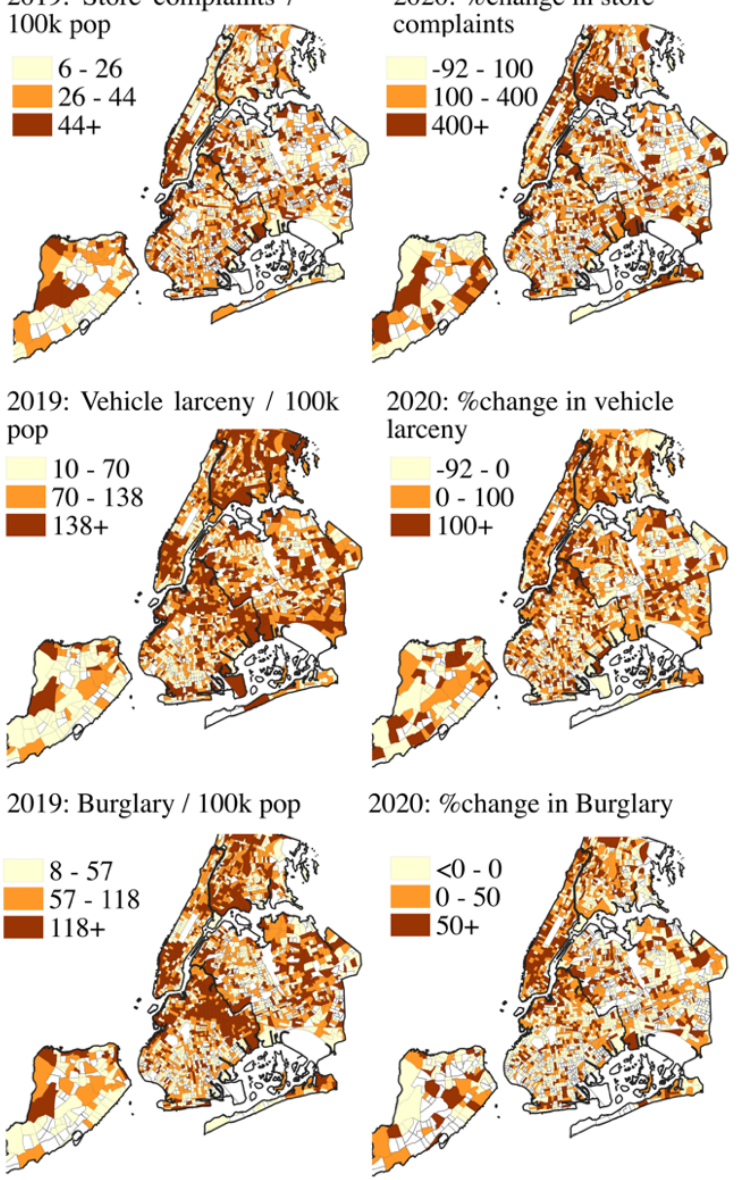

2020: \%change in Burglary

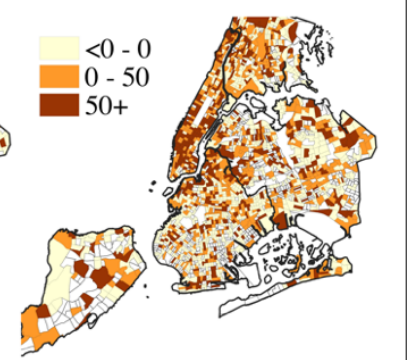

Figure 6. population normalized total incidents between April and November 2019, calculated with equation 2 (left). Percent change in 2020, calculated with equation 3 (right). 
In equation (1), $\overline{x_{1}}$ and $\overline{x_{2}}$ are the mean, $\mathrm{s}_{1}$ and $\mathrm{s}_{2}$ are the standard deviation, and $n_{1}$ and $n_{2}$ are the sample size of the two groups. The significance of the t-value can be determined by comparing the computed t-value with the critical score from the t-table or by observing the p-value. P-value less than 0.05 indicates significant difference between the two-sample means and reject the null hypothesis.

We considered socioeconomic features, including race, income, education as well as COVID infection, and created two groups for each of the features based on the median value at the census tract level. We performed the t-test to determine whether there were statistically significant differences in the determinants of residential satisfaction between the two groups of each feature. Table-1 shows the features and their respective groups to conduct the t-test.

For each noise and safety factor we computed the population normalized total complaints in 2019 and percent change in complaints in 2020 . These can be formulated as follows,

$$
\begin{aligned}
& \text { 2019factor (i) }=\frac{\text { incidents }(i) \text { in } 2019}{\text { population }} \times 100,000 \\
& \% \text { factor(i) }=\frac{\text { incidents }(i) \text { in } 2020-\text { incidents }(i) \text { in } 2019}{\text { incidents }(\text { i } \text { in } 2019} X 100
\end{aligned}
$$

Here, factor $(i)=$ residential noise, vehicular noise, retail store complaints, vehicle larceny, burglary, and illegal fireworks. We used total incidents between April and November for 2019 and 2020. For illegal fireworks complaints, we did not calculate percent change, rather we used per capita 311 calls in 2020 as there were not many fireworks incidence in 2019. Spatial distribution of population normalized total incidences in 2019 and percent change in 2020 is shown in Figure 6. By Welch's ttest with 2019 values, we observed how the factors of noise and safety varies across different racial, economic, and education groups in pre-pandemic times. By t-test with percent change values in 2020, we evaluated the change dynamics of the residential environment due to the pandemic. Figure 7 shows the result of the t-test for two groups of different features mentioned in table-1.

In the pre-pandemic era (2019), per capita complaints related to residential noise in Black and Latinx majority census tracts were higher than White and Asian majority census tracts with statistical significance $(\mathrm{t}$-value $=5.91)$. This implies racial disparity in noise exposure across the city. However, during the pandemic lockdown, residential noise increased almost everywhere, and the difference in the percent change of residential noise between these two groups does not have statistical significance. However, we found the Black and Latinx communities experienced a higher percent increase in vehicular noise during the pandemic than White and Asian communities $(\mathrm{t}$-value $=2.48)$. We also found the statistical significance of racial disparity in price gouging during the pandemic. In 2019, per-capita consumer retail store complaints were higher in White and Asian majority census tracts. However, in 2020, compared to White or Asian communities, Black and Latinx communities generated significantly higher positive percent change $(\mathrm{t}$-value $=$ 4.40) in consumer retail complaints, implying these communities suffered more from price gouging. During the prepandemic era, the financially affluent census tracts with a median income of more than 69,500 USD, enjoyed a better residential environment with significantly lower residential noise $(\mathrm{t}$-value $=-4.80)$ and crime related to vehicle larceny (tvalue $=-2.45)$ and burglary ( $\mathrm{t}$-value $=-2.03$ ) than financially disadvantaged census tracts having median income less than 69,500 USD. During the pandemic, the percent change of these

\begin{tabular}{|c|c|}
\hline Features & Groups for the t-test \\
\hline Black/Latinx & $\begin{array}{l}\text { Group 1: Black or Latinx majority } \\
\text { census tracts }\left(\mathrm{n}_{1}=1125\right) \\
\text { Group 2: White and Asian majority } \\
\text { census tracts }\left(\mathrm{n}_{2}=998\right)\end{array}$ \\
\hline Income & $\begin{array}{l}\text { Group 1: Census tracts having median } \\
\text { household income more than } 69,500 \\
\text { USD }\left(\mathrm{n}_{1}=1062\right) \\
\text { Group 2: Census tracts having median } \\
\text { household income less than } 69,500 \\
\text { USD }\left(\mathrm{n}_{2}=1061\right) \\
\text { (Here census tract level median } \\
\text { household income in NYC }(\$ 69,500) \\
\text { used as the threshold) }\end{array}$ \\
\hline Bachelor & $\begin{array}{l}\text { Group 1: Census tracts having more } \\
\text { than } 21 \% \text { population with bachelor's } \\
\text { degree }\left(\mathrm{n}_{1}=764\right) \\
\text { Group 2: Census tracts having less } \\
\text { than } 21 \% \text { population with bachelor's } \\
\text { degree. }\left(\mathrm{n}_{2}=1359\right) \\
\text { (Here } 21 \% \text { is the city-wide mean } \\
\text { value) }\end{array}$ \\
\hline COVID19 & $\begin{array}{l}\text { Group 1: Census tracts having more } \\
\text { than } 3570 \text { infections per } 100,000 \\
\text { people }\left(\mathrm{n}_{1}=1065\right) \\
\text { Group 2: census tracts having less than } \\
3570 \text { infection per } 100,000 \text { people. ( } \mathrm{n}_{2} \\
=1058) \\
\text { (Here, } 3570 \text { infections per } 100,000 \\
\text { people is the median infection at } \\
\text { census tract level up to November } \\
\text { 30th, 2020.) }\end{array}$ \\
\hline
\end{tabular}
complaints also significantly lower in affluent areas.
Table 1. features and groups for t-test. Sample size for two groups is denoted as $n_{1}$ and $n_{2}$.

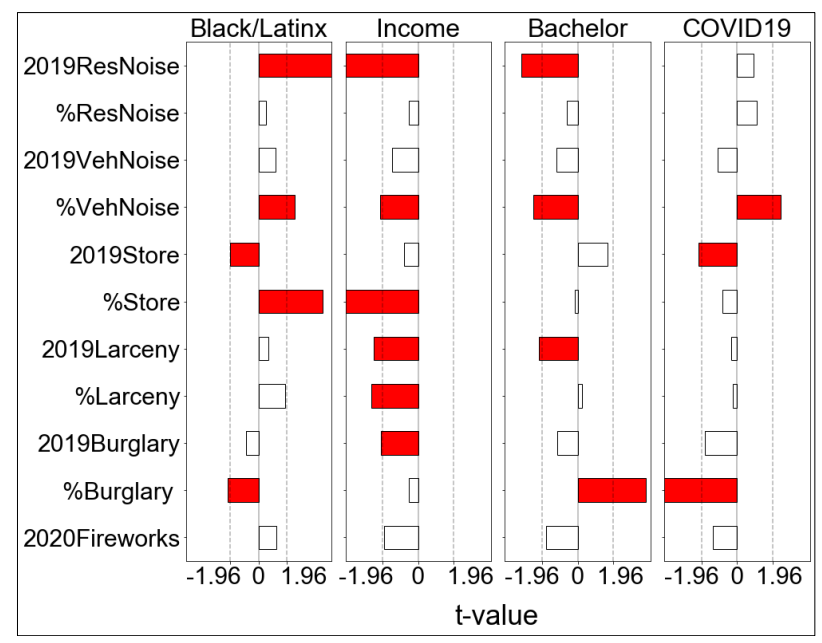

Figure 7. Result of the t-test comparing group-1 to group-2 of different features (table-1). Factors for noise and safety shown on the left side of the chart is calculated with equation 2 and 3 . Factors with red bars have statistical significance, where hollow ones are statistically insignificant. Statistical significance is determined if the absolute value of t-statistics is more than 1.96 and the $\mathrm{p}$-value less than 0.05 .

Before the pandemic, there was no significant difference in percapita consumer retail complaints between rich and poor areas ( $t$ value $=-0.77)$. Nevertheless, the percent change in consumer retail store complaints during COVID19 was significantly high in the census tracts with low income $(\mathrm{t}$-value $=-5.15)$. This 
indicates either local retail stores in low-income areas disproportionately increased the price of products or prices increased everywhere in the city, but complaints were filed more from the low-income neighbourhoods than the high-income areas. The study also found that the area where the higher percentage of people with a college education live, exposed to less noise and generated fewer noise-related complaints. However, these areas experienced relatively higher burglary incidents during the pandemic $(\mathrm{t}$-value $=3.75)$. We also found a significant increase in percent change in vehicular noise during the pandemic in the places with a high COVID-19 infection rate ( $\mathrm{t}$-value $=2.37$ ). However, the change in residential noise does not have statistical significance with the severity of the pandemic. Finally, we found the fireworks incidence occurred everywhere (Figure 2), and the magnitude of the incidences did not associate with the socioeconomic characteristics of the city.

\section{CONCLUSION}

Residential satisfaction is a well-established concept related to resident's wellbeing and happiness. Noise and safety are two significant determinants for residential satisfaction. During the COVID-19 pandemic lockdown, most New Yorkers remained at home after the state issued stay-at-home order, and the city has experienced an enormous change in citizen complaints related to noise and safety. With crowdsourced NYC311 and NYPD911 datasets, this study investigated the change dynamics of residential satisfaction with noise and safety over time and space. Here, we observed three kinds of noise complaints: noise from neighbours, vehicles, and illegal fireworks. We used consumer complaints about price gouging to discern the dynamics of economic safety where vehicle larceny and burglary for physical safety during the pandemic. Comparing to 2019, during the pandemic total residential noise and vehicular complaints increased $100 \%$ in the city. Loud music from neighbours and vehicles was the prime cause of these complaints. NYC also experienced a tremendous increase in illegal fireworks incidences, with nearly 50,000 complaints in 2020 compared to around 900 complaints in 2019 . The majority of these complaints were filed late at night. The study also finds an increase in consumer complaints related to price gouging in retail stores. Welsch's t-test proves that the price gouging complaints disproportionately increased in Black and Latinx majority communities and areas with low income. This might be because of racial and economic disparity in price gouging in the city or more complaints filed from low-income communities where the burden of price gouging is higher. In the pre-pandemic era, per-capita residential noise complaints in Black and Latinx majority places were higher than the White and Asian majority areas with statistical significance, indicating the racial disparity in noise exposure. But, during the pandemic, there was no significant difference in the percent increase in residential noise complaints between these two groups, indicating all residents of NYC were exhausted by the noise by neighbours regardless of race. We also found the communities with higher income have higher residential satisfaction with low noise and crime. Areas with a higher percentage of college graduates have lower noise exposure, but during COVID-19, crime related to burglary increased in such areas. Finally, regardless of the socioeconomic characteristics of the city, illegal fireworks increased everywhere during the pandemic.

With citizen-generated data, this study demonstrated a reduction in the overall residential satisfaction in the city during the pandemic with excessive noise exposure and reduced safety. With statistical justification, the study also exposed the racial and economic disparity in residential satisfaction with disproportionately higher baseline noise exposure, along with disproportionately lower physical and economic safety in Black, Latinx, and poor neighbourhoods. Authorities could take necessary initiatives to remedy these inequalities to ensure a better environment for all the residents. The study also opens up the window for further research from the domains of sociology, architecture, city planning, geography and others to improve the level of residential satisfaction of New Yorkers.

\section{ACKNOWLEDGEMENTS}

We greatly acknowledge the doctoral research fellowship from NYU Tandon School of Engineering.

\section{REFERENCES}

abc7NY, 2020. Coronavirus NYC: Stores fined for COVID-19 price gouging. https://abc7ny.com/price-gouging-finescoronavirus-nyc-update/6090898/ (29 March 21).

Abdullah, M.I., Zainul Abidin, N., Basrah, N., Alias, M.N., 2020. Conceptual Framework of Residential Satisfaction. Environment-Behaviour Proceedings Journal 5, 229-235. https://doi.org/10.21834/ebpj.v5i14.2239

Adriaanse, C.C.M., 2007. Measuring residential satisfaction: A residential environmental satisfaction scale (RESS). Journal of Housing and the Built Environment 22, 287-304. https://doi.org/10.1007/s10901-007-9082-9

Amole, D., 2009. Residential satisfaction in students' housing. Journal of Environmental Psychology 29, 76-85. https://doi.org/10.1016/j.jenvp.2008.05.006

Basner, M., Babisch, W., Davis, A., Brink, M., Clark, C., Janssen, S., Stansfeld, S., 2014. Auditory and non-auditory effects of noise on health. The Lancet. https://doi.org/10.1016/S0140-6736(13)61613-X

Bosch, A., Kannenkeril, D., Rauh, M., Ott, C., Striepe, K., Jung, S., Kolwelter, J., Schmieder, R.E., 2021. RELATION BETWEEN NOISE ANNOYANCE, STRESS HORMONES AND THE RENAL HEMODYNAMIC. Journal of Hypertension 39, e178. https://doi.org/10.1097/01.hjh.0000746396.62725.e5

Daiber, A., Kröller-Schön, S., Oelze, M., Hahad, O., Li, H., Schulz, R., Steven, S., Münzel, T., 2020. Oxidative stress and inflammation contribute to traffic noise-induced vascular and cerebral dysfunction via uncoupling of nitric oxide synthases. Redox Biology. https://doi.org/10.1016/j.redox.2020.101506

Demao, B., 1991. Residential environments. Habitat International 15, 139-141. https://doi.org/10.1016/01973975(91)90037-L

Emami, A., Sadeghlou, S., 2020. Residential Satisfaction: A Narrative Literature Review Towards Identification of Core Determinants and Indicators. Housing, Theory and Society. https://doi.org/10.1080/14036096.2020.1844795

Feldmane, L., 2020. Socio-Spatial differentiation of residential Satisfaction in Injelgava. Riga. Doctoral Thesis. University of Latvia

Feuer, W., Higgins-Dunn, N., 2020. Coronavirus: Cuomo orders most New Yorkers to stay inside - "we're all under quarantine now". $\quad$ https://www.cnbc.com/2020/03/20/new-york-gov- 
cuomo-orders-100percent-of-non-essential-businesses-to-workfrom-home.html (6 December 2020).

Galster, G.C., Hesser, G.W., 1981. Residential Satisfaction. Environment and Behavior 13, 735-758. https://doi.org/10.1177/0013916581136006

Greenbaum, J., 2020. New NYC Price Gouging Rule Goes Into Effect and NYC Settles Price Gouging Case With Metro Drugs. https://advertisinglaw.fkks.com/post/102gahr/new-nyc-pricegouging-rule-goes-into-effect-and-nyc-settles-price-gougingcase-wi (29 March 2021).

Hicks, N., Marsh, J., 2020. Illegal fireworks complaints in NYC soar under lockdown. https://nypost.com/2020/06/15/illegalfireworks-complaints-in-nyc-soar-under-lockdown/ (4 April 2021).

Ising, H., Kruppa, B., 2004. Health effects caused by noise: Evidence in the literature from the past 25 years. Noise and Health 6, 5-13.

Jagun, A., Brown, D.R., Milburn, N.G., Gary, L.E., 1990. Residential Satisfaction and Socioeconomic and Housing Characteristics of Urban Black Adults. Journal of Black Studies $21,40-51$.

Kilgannon, C., Kim, J., 2020. New Woe for a Jittery N.Y.C.: Illegal Fireworks Going Off All Night - The New York Times. https://www.nytimes.com/2020/06/19/nyregion/fireworksevery-night-nyc.html (30 March 2021).

Kim, T.K., 2015. T test as a parametric statistic. Korean Journal of Anesthesiology 68, 540-546. https://doi.org/10.4097/kjae.2015.68.6.540

Knoll, C., 2020. Panicked Shoppers Empty Shelves as Coronavirus Anxiety Rises - The New York Times. https://www.nytimes.com/2020/03/13/nyregion/coronaviruspanic-buying.html (4 April 2021).

Krauth, D., 2020. Pandemic partying in NYC causing rise in noise complaints 7 On Your Side investigates - ABC7 New York. https://abc7ny.com/nyc-noise-complaints-street-partiesillegal-fireworks-looting/6380338/ (9 April 2021)

Kshetrimayum, B., Bardhan, R., Kubota, T., 2020. Factors Affecting Residential Satisfaction in Slum Rehabilitation Housing in Mumbai. Sustainability 12, 2344. https://doi.org/10.3390/su12062344

Lu, M., 1999. Determinants of Residential Satisfaction: Ordered Logit vs. Regression Models, Growth and Change. https://doi.org/10.1111/0017-4815.00113

McKinley, J., Gold, M., 2020. Ban on Large Gatherings in N.Y. as Coronavirus Cases Rise Sharply - The New York Times. https://www.nytimes.com/2020/03/12/nyregion/coronavirusnyc-event-ban.html (9 December 2020).

Najib, N.U.M., Yusof, N.A., Osman, Z., 2011. The-Influenceof-Socio-Economic-Backgrounds-towards-Satisfaction-withStudent-Housing-Facilities. International Journal of Educational and Pedagogical Sciences 5.

New York State Pressroom, 2020. Governor Cuomo Signs Legislation Banning Price Gouging of Personal Protective
Equipment. https://www.governor.ny.gov/news/governorcuomo-signs-legislation-banning-price-gouging-personalprotective-equipment (4 April 2021).

$\mathrm{Ng}$, C.F., 2000. Effects of building construction noise on residents: A quasi-experiment. Journal of Environmental $\begin{array}{lll}\text { Psychology } & 20, & 375-385\end{array}$ https://doi.org/10.1006/jevp.2000.0177

Norouzi, M., Meshkini, A., Khademi, S., 2020. Impact of socioeconomic characteristics on neighborhood environment satisfaction in deteriorated areas, in: Research Handbook on Community Development. Edward Elgar Publishing, pp. 301318. https://doi.org/10.4337/9781788118477.00025

Noy, I., 2018. The Ethical Content of the Economic Analysis of Disasters: Price Gouging and Post-Disaster Recovery, in: Advancing Global Bioethics. Springer Science and Business Media B.V., pp. 55-68. https://doi.org/10.1007/978-3-31992722-0 5

NYC 311, 2021. Store Complaint https://portal.311.nyc.gov/article/?kanumber=KA-02153 (26 March 2021).

NYC 911 Reporting, 2021. Anatomy of a 911 Call. https://www1.nyc.gov/site/911 reporting/reports/reports.page (11 April 2021)

NYC Consumer and Worker Protection, 2020. Uneven Impact: What Job Loss During COVID-19 Means for New Yorkers Now and into the Future. https://www1.nyc.gov/assets/dca/downloads/pdf/partners/Uneve n_Impact.pdf (13 April 2021)

NYC Health, 2020a. Coronavirus Disease 2019 (COVID-19) : Daily Data Summary (May 15, 2020 at 6:00 PM) https://www1.nyc.gov/assets/doh/downloads/pdf/imm/covid-19daily-data-summary-05162020-1.pdf (19 September 2020).

NYC Health, 2020b. COVID-19: Data. https://www1.nyc.gov/site/doh/covid/covid-19-data.page. (3 September 2020).

NYC Office of the Mayor, 2020. Mayor de Blasio Announces 311's Record-Setting 23.5 Million Calls in 2020. https://www1.nyc.gov/office-of-the-mayor/news/893-20/mayorde-blasio-311-s-record-setting-23-5-million-calls-2020 (1 April 2021).

NYC Office of the Mayor, 2013. Mayor Bloomberg Commemorates Ten Years of NYC311, the Nation's Largest and Most Comprehensive 311 Service. https://wwwl.nyc.gov/officeof-the-mayor/news/089-13/mayor-bloomberg-commemoratesten-years-nyc311-nation-s-largest-most-comprehensive-311 (14 March 2021).

NYC Open Data, 2021a. 311 Service Requests from 2010 to Present. https://data.cityofnewyork.us/Social-Services/311Service-Requests-from-2010-to-Present/erm2-nwe9 (10 March 2021).

NYC Open Data, 2021b. NYPD Calls for Service. https://data.cityofnewyork.us/Public-Safety/NYPD-Calls-forService/n2zq-pubd (21 March 2021).

NYPD Newsroom, 2021. Overall Crime in New York City Reaches Record Low in 2020. City of New York; 
https://www1.nyc.gov/site/nypd/news/p0106a/overall-crimenew-york-city-reaches-record-low-2020 (21 March 2021).

Pishgahi, S., Partovi, P., 2020. Evaluating the effects of cross neighborhood facilities on residential satisfaction by developing importance-satisfaction rate method (case study: Jahanshahr neighborhood of Karaj, Iran). Journal of Housing and the Built Environment 1-34. https://doi.org/10.1007/s10901-020-097615

Ruxton, G.D., 2006. The unequal variance t-test is an underused alternative to Student's t-test and the Mann-Whitney U test. Behavioral Ecology 17, 688-690. https://doi.org/10.1093/beheco/ark016

Sam, M., Zain, M.F.M., Saadatian, O., 2012. Residential satisfaction; Meaning and interpretation, in: BEIAC 2012 - 2012 IEEE Business, Engineering and Industrial Applications Colloquium. 279-283. https://doi.org/10.1109/BEIAC.2012.6226067

Shahgholi, H., 2020. Low income and minority residents held to ransom by pandemic price gouging. https://www.amny.com/coronavirus/low-income-minorityresidents-nyc-pandemic/ (29 March 2021).

Stauss, B., Neuhaus, P., 1997. The qualitative satisfaction model. International Journal of Service Industry Management 8, 236-249. https://doi.org/10.1108/09564239710185424

Tao, Y., Chai, Y., Kou, L., Kwan, M.P., 2020. Understanding noise exposure, noise annoyance, and psychological stress: Incorporating individual mobility and the temporality of the exposure-effect relationship. Applied Geography 125, 102283. https://doi.org/10.1016/j.apgeog.2020.102283

Terzano, K., 2014. Residential Satisfaction, in: Michalos, A.C. (Ed.), Encyclopedia of Quality of Life and Well-Being Research. Springer Netherlands, Dordrecht, pp. 5526-5527. https://doi.org/10.1007/978-94-007-0753-5_2491

U.S. Census Bureau, 2018. 2014-2018 American Community Survey 5-Year Estimates.

Waziri, A.G., Yusof, A., Md Sani, N., Rahim, A., Roosli, R., Yakub, A.A., 2014. How Socioeconomic Status (SES) Predicts Housing Satisfaction in Nigeria. International Journal of Managerial Studies and Research 2, 95-104.

Wu, W., Dong, G., SUN, Y., Yun, Y., 2020. Contextualized effects of Park access and usage on residential satisfaction: A spatial approach. Land Use Policy 94, 104532. https://doi.org/10.1016/j.landusepol.2020.104532

Youssoufi, S., Houot, H., Vuidel, G., Pujol, S., Mauny, F., Foltête, J.C., 2020. Combining visual and noise characteristics of a neighborhood environment to model residential satisfaction: An application using GIS-based metrics. Landscape and Urban Planning 204, 103932. https://doi.org/10.1016/j.landurbplan.2020.103932

Zaveri, M., Gold, M., 2020. New York City Announces Crackdown on Illegal Fireworks - The New York Times. https://www.nytimes.com/2020/06/23/nyregion/fireworksnyc.html (4 April 2021). 